\title{
PIGMENTED VILLONODULAR SYNOVITIS OF THE KNEE JOINT: A CASE REPORT
}

\author{
Ravi Bhushan Raman1, Reecha Singh², Vijayanand Choudhary33, Sanjeet Kumar Singh ${ }^{4}$
}

${ }^{1}$ Senior Resident, Department of Pathology, Indira Gandhi Institute of Medical Sciences (IGIMS), Patna.

${ }^{2}$ Associate Professor, Department of Pathology, Indira Gandhi Institute of Medical Sciences (IGIMS), Patna.

${ }_{3}^{3}$ Additional Professor, Department of Pathology, Indira Gandhi Institute of Medical Sciences (IGIMS), Patna.

${ }^{4}$ Associate Professor, Department of Pathology, Indira Gandhi Institute of Medical Sciences (IGIMS), Patna.

\section{ABSTRACT}

A 23-year-old girl presented with an insidious gradually progressing swelling over the right knee for one year with occasional pain. There was no history of any injury and laboratory studies were normal. On fine needle aspiration cytology, a probable diagnosis of pigmented villonodular synovitis was made, confirmed on biopsy. The lesion was excised and the patient has not had a recurrence in one year. This case report emphasises that the diagnoses of pigmented villonodular synovitis should be considered in any case of chronic joint effusion.

\section{KEYWORDS}

Pigmented, Villonodular Synovitis, Knee Joint.

HOW TO CITE THIS ARTICLE: Raman RB, Singh R, Choudhary V, et al. Pigmented villonodular synovitis of the knee joint: a case report. J. Evolution Med. Dent. Sci. 2016;5(72):5329-5330, DOI: 10.14260/jemds/2016/1208

\section{INTRODUCTION}

Pigmented Villonodular Synovitis (PVNS) is a disease of synovial membrane characterised by a proliferation of mononuclear cells, probably of histiocytic origin, deep to the synovial lining cells. In addition to mononuclear cells, multinucleated giant cells, foam cells and haemosiderophages are present in varying amounts. As a result of these cells the synovial membrane, either intra-articular or extra-articular is transformed into thickened brownish nodules and greatly elongated villi. The initial clinical symptoms are indistinguishable from bacterial synovitis or rheumatoid arthritis. Surgical treatment includes synovectomy and tenosynovectomy. PVNS is locally aggressive and tends to recur if incompletely excised.

\section{CASE HISTORY}

A 23-year-old female presented with an insidious gradually progressing swelling over the right knee for one year with occasional pain. She had no history of trauma. Examination revealed a $6 \times 4 \mathrm{~cm}$ swelling, non-tender, non-compressible, soft in consistency over the right knee, effusion grade IV. Movements of knee was moderately reduced. On investigations her ESR, ASO titre, serum uric acid and complete blood count were within normal limits. Radiograph of knee did not reveal any bony abnormality. MRI findings revealed fluid and abnormal soft tissue material of medium signal intensity (Fig. 1) with no bony involvement. Radiologically and clinically differentials included haemophilia, PVNS, rheumatoid arthritis and severe infective arthritis. Fine needle aspiration cytology was reported as suggestive of PVNS (Fig. 2). Total excision was done preserving the tendons, vessels and nerves.

Financial or Other, Competing Interest: None.

Submission 28-02-2016, Peer Review 25-08-2016,

Acceptance 01-09-2016, Published 08-09-2016.

Corresponding Author:

Dr. Reecha Singh,

Quarter No. E2/2,

Indira Gandhi Institute of

Medical Sciences (IGIMS),

Patna-14.

E-mail: sreecha@ymail.com

DOI: 10.14260/jemds/2016/1208

(c) $\bigcirc$
The gross pathological findings included a specimen measuring $5 \times 3 \times 2 \mathrm{~cm}$ with a soft consistency and grey white colour with bosselated surface. The cut surface showed a variegated appearance with alternate dark and grey white areas (Fig. 3). On histological examination, sections showed a tumour made up of predominantly closely packed medium sized polyhedral cells with variable admixture of multinucleated giant cells and haemosiderin-laden macrophages (Fig. 4). Mitosis was inconspicuous. There were focal areas of hyalinisation. Papillary projections were made up of foamy macrophages.

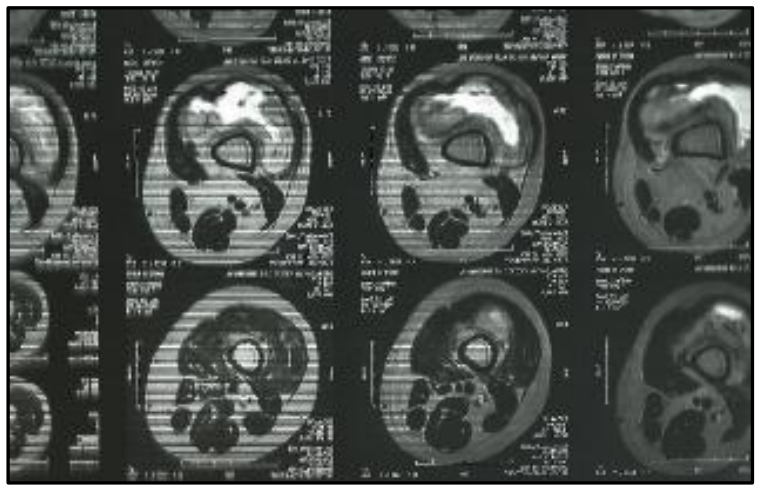

Fig. 1: A T1-Weighted MRI of the Knee of Patient. There is Significant Effusion in Periarticular Bursae as well as Diffuse Synovial Thickening

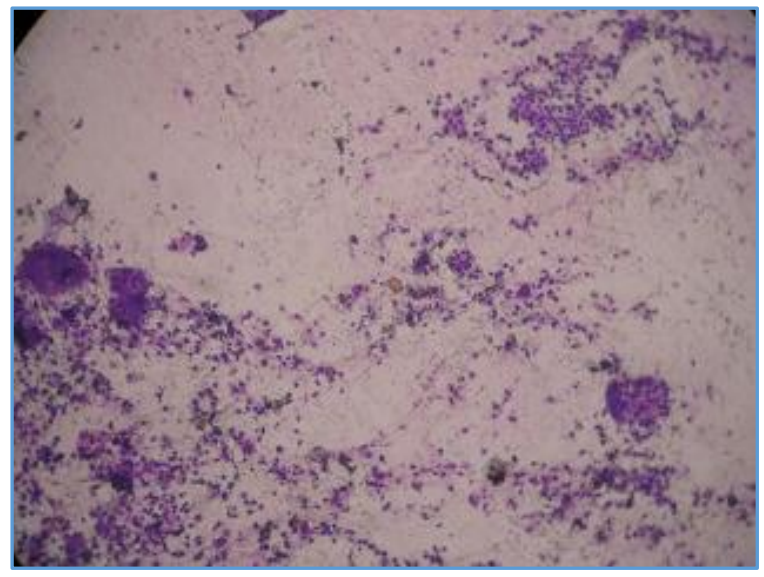

Fig. 2: FNAC Smear shows Mononuclear Cells Characteristic of PVNS contain Haemosiderin

(Giemsa 200X) 


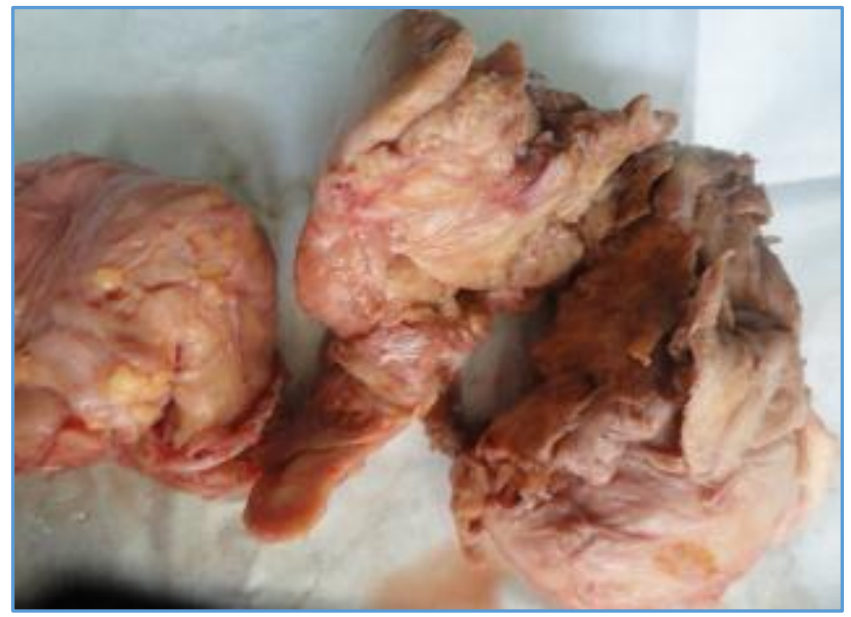

Fig. 3: Gross Specimen with a Soft Consistency and Grey White Colour

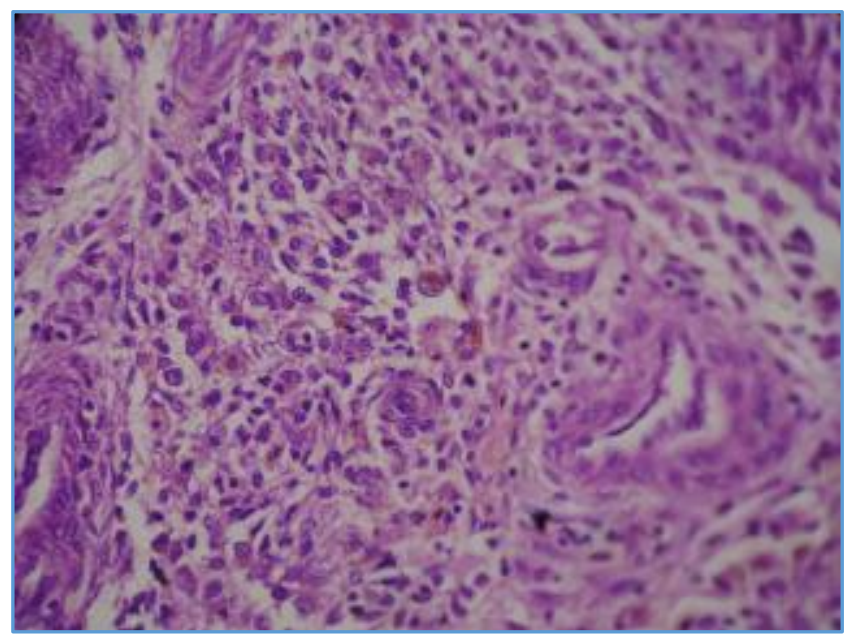

Fig. 4: Histology showing Tumour Comprising of Polyhedral Cells, Giant Cells and Haemosiderin Laden Macrophages (H \& E Stain - 400X)

\section{DISCUSSION}

Pigmented villonodular synovitis occurs in one of two growth patterns-a localised nodule or a diffuse villous hyperplasia of large portions of synovial membrane as in our case. The localised form, when arising in tenosynovium, is sometimes called giant cell tumour of tendon sheath. The aetiology of pigmented villonodular synovitis is uncertain. Since many of the mononuclear cells show trisomy 7 , a feature which suggests clonality, a neoplastic origin is possible. ${ }^{1} \mathrm{~A}$ neoplastic origin is further supported by the observation that some cells in this process are aneuploid. ${ }^{2}$ Another observation has confirmed the histiocytic differentiation of the mononuclear cells - most contain the histiocyte markers Leu-M3 and Leu3.3. Disturbances of metabolism, trauma and haemorrhages are other possible aetiologies. ${ }^{3}$
PVNS may be intra- or extra-articular and can present in the diffuse or nodular form with a tendency to bleed and erode bone. Joint effusion can be out of proportion to the mild degree of pain and absence of bloody effusion does not rule out PVNS. Radiologically, there is bone preservation and relative lack of hypertrophic bone or spur formation in PVNS can help differentiate this condition from osteoarthritis.4,5 Pigmented villonodular synovitis most commonly affects adult patients in the third or fourth decades of life; however, our case had a younger onset. Patients present with joint pain, swelling and stiffness. The diagnosis of pigmented villonodular synovitis was not suspected clinically in most reported cases similar to our case. In our case, repeated fine needle aspiration elsewhere revealed only blood, so a thorough workup for haemophilia was done which was subsequently ruled out. In our case arthroscopic synovectomy was done, which is the treatment of choice. ${ }^{6}$ Arthroscopic synovectomy has reduced morbidity and is well tolerated by patients. Open surgical synovectomy causes stiffness and pain and has a long recovery time, mainly after procedures involving the knee joint. Thereafter, the patient had no complaints. No follow-up biopsies or arthroscopies were performed, as it was simple to follow up the patient with clinical examinations, plain X-rays and MRI in particular.

Pigmented villonodular synovitis should be considered when a patient presents with a painful swollen knee, has laboratory and clinical studies which do not support a diagnosis of bacterial synovitis or juvenile rheumatoid arthritis.

\section{REFERENCES}

1. Ray RA, Morton CC, Lipinski KK, et al. Cytogenetic evidence of clonality in a case of pigmented villonodular synovitis. Cancer 1991;67(1):121-5.

2. Abdul-Karim FW, el-Naggar AK, Joyce MJ, et al. Diffuse and localized tenosynovial giant cell tumor and pigmented villonodular synovitis: a clinicopathologic and flow cytometric DNA analysis. Hum Pathol 1992;23(7):729-35.

3. Ohjimi $Y$, Iwasaki $H$, Ishiguro $M$, et al. Short arm of chromosome 1 aberration recurrently found in pigmented villonodular synovitis. Cancer Genet Cytogenet 1996;90(1):80-5.

4. Dorwart RH, Genant HK, Johnston WH, et al. Pigmented villonodular synovitis of synovial joints: clinical, pathologic and radiologic features. AJR Am J Roentgenol 1984;143(4):877-85.

5. Jacobson JA, Jamadar DA, Ellis JH, et al. Pigmented villonodular synovitis and related lesions: the spectrum of imaging findings. AJR Am J Roentgenol 1999;172(1): 191-7.

6. Neubauer $\mathrm{P}$, Weber $\mathrm{K}$, Miller $\mathrm{NH}$, et al. Pigmented villonodular synovitis in children: a report of six cases and review of the literature. Iowa Orthop J 2007;27:90-4. 